\title{
Controle de brusone e manejo de nitrogênio em cultivo de arroz irrigado
}

\author{
Nand Kumar Fageria(1) e Anne Sitarama Prabhu(1) \\ (1)Embrapa Arroz e Feijão, Caixa Postal 179, CEP 75375-000 Santo Antônio de Goiás, GO. E-mail: fageria@cnpaf.embrapa.br,
} prabhu@cnpaf.embrapa.br

\begin{abstract}
Resumo - Informações sobre práticas culturais, tais como a aplicação de $\mathrm{N}$ e o controle de doenças causadas por fungos, em solo de várzea do Brasil são insuficientes. O objetivo deste trabalho foi avaliar a resposta do arroz irrigado a épocas de aplicação de $\mathrm{N}$ e ao tratamento das sementes com fungicida no controle de brusone. Aplicaram-se $90 \mathrm{~kg} \mathrm{ha}^{-1}$ de $\mathrm{N}$ da seguinte forma: todo no plantio $\left(\mathrm{T}_{1}\right) ; 1 / 3$ no plantio, 1/3 45 dias após o plantio e $1 / 3$ na iniciação do primórdio floral $\left(\mathrm{T}_{2}\right) ; 1 / 2$ no plantio e $1 / 245$ dias após o plantio $\left(\mathrm{T}_{3}\right) ; 1 / 2$ no plantio e $1 / 2$ na iniciação do primórdio floral $\left(\mathrm{T}_{4}\right) ; 2 / 3$ no plantio e $1 / 345$ dias após o plantio $\left(\mathrm{T}_{5}\right) ; 2 / 3$ no plantio e 1/3 aplicado na iniciação do primórdio floral $\left(\mathrm{T}_{6}\right)$ e $1 / 3$ no plantio e $2 / 320$ dias após o plantio $\left(\mathrm{T}_{7}\right)$. O fungicida pyroquilon foi aplicado nas doses de 0,200 e $400 \mathrm{~g}$ de ingrediente ativo por $100 \mathrm{~kg}$ de sementes. A produção de grãos foi influenciada significativamente pela época de aplicação de $\mathrm{N}$ e pelo tratamento de fungicida. A aplicação de $\mathrm{N}$ influenciou significativamente a matéria seca da parte aérea e a acumulação de $\mathrm{N}$ nos grãos. A produção máxima de grãos foi obtida pelos tratamentos $\mathrm{T}_{2}$ e $\mathrm{T}_{3}$. $\mathrm{O}$ tratamento com $200 \mathrm{~g}$ de fungicida por $100 \mathrm{~kg}$ de sementes aumentou significativamente a produção de grãos, em relação à testemunha.
\end{abstract}

Termos para indexação: Oryza sativa, rendimento, controle de doenças.

\section{Blast control and nitrogen management in lowland rice cultivation}

\begin{abstract}
Nitrogen timing and control of fungal diseases are cultural practices in lowland rice production. The objective of this study was to determine appropriate timing of $\mathrm{N}$ application and adequate rate of seed treatment with pyroquilon fungicide in lowland rice. The $90 \mathrm{~kg} \mathrm{ha}^{-1} \mathrm{~N}$ application timing were alloted as follows: total at sowing $\left(\mathrm{T}_{1}\right) ; 1 / 3$ at sowing, $1 / 3$ at active tillering and $1 / 3$ at panicle initiation $\left(\mathrm{T}_{2}\right) ; 1 / 2$ at sowing and $1 / 2$ at active tillering $\left(\mathrm{T}_{3}\right) ; 1 / 2$ at sowing and $1 / 2$ at panicle initiation $\left(\mathrm{T}_{4}\right) ; 2 / 3$ at sowing and $1 / 3$ at active tillering $\left(\mathrm{T}_{5}\right) ; 2 / 3$ at sowing and $1 / 3$ at panicle initiation $\left(\mathrm{T}_{6}\right)$; and $1 / 3$ at sowing and $2 / 3$ at the start of tillering $\left(\mathrm{T}_{7}\right)$. Fungicide treatments were 0,200 , and $400 \mathrm{~g}$ active ingredient pyroquilon per $100 \mathrm{~kg}$ seed. Grain yield was significantly affected with timing of $\mathrm{N}$ application and fungicide treatments. Nitrogen treatment also affected significantly straw yield, and $\mathrm{N}$ uptake in grain. Maximum grain yield was obtained with treatments T2 and T3. Fungicide treatment of $200 \mathrm{~g}$ per100 kg of seed, produced significantly higher yield as compared to the control.
\end{abstract}

Index terms: Oryza sativa, yield, disease control.

\section{Introdução}

$\mathrm{O}$ uso eficiente de $\mathrm{N}$ é significativo no aumento da produção de culturas anuais, como o arroz. Fertilizantes nitrogenados, entretanto, podem poluir o meio ambiente, se não forem utilizados na dose adequada e aplicados de modo correto. A eficiência de recuperação do $\mathrm{N}$ pela cultura do arroz irrigado situa-se entre $32 \%$ e $49 \%$ nos solos de várzea do Brasil Central, dependendo da dose de aplicação (Fageria et al., 2003). Existe grande possibilidade de lixiviação de nitrato nos solos de várzea, podendo causar poluição na água subterrânea. Porém, o aumento na eficiência do uso de $\mathrm{N}$ por meio de práticas culturais pode aumentar substancialmente a produtividade do arroz, sem custo adicional dos insumos e amenizar o problema da contaminação ambiental (Kundu et al., 1996; Balasubramanian et al., 1999).

A utilização de doses, época de aplicação e parcelamento, de acordo com a necessidade da planta de arroz, pode aumentar significativamente a eficiência do uso dos fertilizantes nitrogenados (Fageria et al., 2003). Quando se aplica toda a dose no plantio do arroz irrigado, $\mathrm{o} N$ pode ser parcialmente perdido por lixiviação, devido à inundação (Fageria et al., 2003).

A brusone, causada pelo fungo Pyricularia grisea Cook. Saccardo, é uma das mais prejudiciais doenças 
do arroz, reduzindo a produtividade, fato verificado na maioria das áreas onde o arroz é cultivado no Brasil (Filippi \& Prabhu, 1998). Portanto, é necessário que seu controle seja feito de forma adequada com o uso de fungicidas, de práticas culturais e de cultivares resistentes (Wang et al., 1989).

Inadequações quanto à dosagem e época de aplicação do N, além de reduzir a produção, aumentam a incidência de doenças nas culturas (Fageria et al., 1997). A influência do $\mathrm{N}$ sobre a brusone varia de acordo com a quantidade, a forma disponível e a suscetibilidade da planta (Huber \& Watson, 1974). A aplicação total de N no sulco, por ocasião do plantio, aumenta significativamente a presença da brusone comparada com a aplicação parcelada desse elemento (Santos et al., 1986).

O objetivo deste trabalho foi avaliar a resposta do arroz irrigado a épocas de aplicação do $\mathrm{N}$ e ao tratamento de sementes com fungicida no controle da brusone.

\section{Material e Métodos}

Foram conduzidos ensaios de campo com o arroz irrigado (Oryza sativa L.) em dois locais, a partir de 1997/ 1998, sendo dois cultivos sucessivos na fazenda da Cobrape (Formoso do Araguaia) e três no Município de Lagoa da Confusão, no Estado do Tocantins. Os solos das áreas experimentais foram classificados como Inceptissols de várzea, e suas propriedades químicas e granulométricas $(0-20 \mathrm{~cm})$, antes da aplicação dos tratamentos, são apresentadas na Tabela $1 . \mathrm{O} \mathrm{pH}$ foi medido em água e o $\mathrm{P}, \mathrm{K}, \mathrm{Cu}, \mathrm{Zn}, \mathrm{Fe}$ e $\mathrm{Mn}$, extraídos pelo extrator Mehlich $1\left(0,05 \mathrm{M} \mathrm{HCl}+0,0125 \mathrm{M} \mathrm{H}_{2} \mathrm{SO}_{4}\right)$. $\mathrm{O} \mathrm{Ca}, \mathrm{Mg}$ e Al foram extraídos com solução de $\mathrm{KCl} 1 \mathrm{M}$. No extrato, o $\mathrm{P}$ foi determinado por colorimetria, o $\mathrm{K}$ por fotometria de chama e os micronutrientes $\mathrm{Cu}, \mathrm{Zn}$, Fe e $\mathrm{Mn}$, por absorção atômica. $\mathrm{O} \mathrm{Ca}$ e o $\mathrm{Mg}$ foram determinados por titulação com EDTA e o Al por titulação com $\mathrm{NaOH}$. A matéria orgânica foi avaliada pelo método de Walkley-Black e a análise granulométrica foi realizada pelo método da pipeta (Embrapa, 1997).

Os tratamentos consistiram de sete fracionamentos de $90 \mathrm{~kg} \mathrm{ha}^{-1}$ de $\mathrm{N}$ (uréia), considerados econômicos para o arroz irrigado em solos de várzea do Brasil Central (Fageria \& Baligar, 2001). A dose de $\mathrm{N}$ foi aplicada toda no plantio $\left(\mathrm{T}_{1}\right) ; 1 / 3$ no plantio, 1/3 45 dias após o plantio e $1 / 3$ na iniciação do primórdio floral $\left(\mathrm{T}_{2}\right) ; 1 / 2$ no plantio e $1 / 245$ dias após o plantio $\left(\mathrm{T}_{3}\right) ; 1 / 2$ no plantio e $1 / 2$ na iniciação do primórdio floral $\left(\mathrm{T}_{4}\right) ; 2 / 3$ no plantio e $1 / 345$ dias após o plantio $\left(\mathrm{T}_{5}\right) ; 2 / 3$ no plantio e $1 / 3$ aplicado na iniciação do primórdio floral $\left(\mathrm{T}_{6}\right)$ e $1 / 3$ no plantio e $2 / 320$ dias após o plantio $\left(\mathrm{T}_{7}\right)$. O fungicida pyroquilon foi aplicado nas doses de 0,200 e $400 \mathrm{~g}$ de ingrediente ativo por $100 \mathrm{~kg}$ de sementes.

Utilizou-se o delineamento experimental de blocos ao acaso, em parcelas subdivididas com três repetições, aplicando-se fertilizante nitrogenado nas parcelas, e fungicida pyroquilon nas subparcelas. A área de cada

Tabela 1. Resultados de análises químicas e granulométricas dos solos das áreas experimentais de cinco cultivos de arroz irrigado antes da aplicação dos tratamentos ${ }^{(1)}$.

\begin{tabular}{|c|c|c|c|c|c|}
\hline \multirow[t]{3}{*}{ Propriedade do solo } & \multicolumn{2}{|c|}{ Formoso do Araguaia } & \multicolumn{3}{|c|}{ Lagoa da Confusão } \\
\hline & 1o cultivo & $2^{\circ}$ c cultivo & 1o cultivo & 2o cultivo & $3^{\circ}$ cultivo \\
\hline & $1997 / 1998$ & 1998/1999 & $1997 / 1998$ & 1998/1999 & $1999 / 2000$ \\
\hline $\mathrm{pH}\left(\mathrm{H}_{2} \mathrm{O}\right)$ & 5,3 & 5,2 & 5,3 & 5,1 & 4,9 \\
\hline $\mathrm{MO}\left(\mathrm{g} \mathrm{kg}^{-1}\right)$ & 30 & 46 & 29 & 23 & 22 \\
\hline $\mathrm{P}\left(\mathrm{mg} \mathrm{kg}^{-1}\right)$ & 135,4 & 167,7 & 5,9 & 3,6 & 15 \\
\hline $\mathrm{K}\left(\mathrm{mg} \mathrm{kg}^{-1}\right)$ & 98 & 120 & 120 & 92 & 90 \\
\hline $\mathrm{Ca}\left(\mathrm{cmol}_{\mathrm{c}} \mathrm{kg}^{-1}\right)$ & 3,8 & 1,7 & 2,6 & 2,1 & 1,4 \\
\hline $\mathrm{Mg}\left(\mathrm{cmol}_{\mathrm{c}} \mathrm{kg}^{-1}\right)$ & 2,7 & 1,5 & 1,6 & 2,2 & 0,5 \\
\hline $\mathrm{Al}\left(\mathrm{cmol}_{\mathrm{c}} \mathrm{kg}^{-1}\right)$ & 1,6 & 0,5 & 1,3 & 1,5 & 0,5 \\
\hline $\mathrm{Cu}\left(\mathrm{mg} \mathrm{kg}^{-1}\right)$ & 2,4 & 1,8 & 1,8 & 1,4 & 2,1 \\
\hline $\mathrm{Zn}\left(\mathrm{mg} \mathrm{kg}^{-1}\right)$ & 2,1 & 6,4 & 2,1 & 0,9 & 5,3 \\
\hline $\mathrm{Fe}\left(\mathrm{mg} \mathrm{kg}^{-1}\right)$ & 187 & 154 & 187 & 143 & 275 \\
\hline $\operatorname{Mn}\left(\mathrm{mg} \mathrm{kg}^{-1}\right)$ & 66 & 16 & 9 & 7 & 6 \\
\hline $\operatorname{Argila}\left(\mathrm{g} \mathrm{kg}^{-1}\right)$ & 500 & 160 & 425 & 470 & 415 \\
\hline Silte $\left(\mathrm{g} \mathrm{kg}^{-1}\right)$ & 275 & 580 & 200 & 225 & 160 \\
\hline Areia $\left(\mathrm{g} \mathrm{kg}^{-1}\right)$ & 225 & 260 & 375 & 305 & 425 \\
\hline
\end{tabular}

${ }^{(1)}$ Os experimentos do segundo e terceiro anos foram conduzidos em locais diferentes dos anos anteriores. 
parcela era de $12 \times 4 \mathrm{~m}$ e da subparcela $4 \times 4 \mathrm{~m}$, com $2 \mathrm{~m}$ de bordadura entre as parcelas principais, separadas com marachas de aproximadamente $50 \mathrm{~cm}$ de altura, para evitar a contaminação de $\mathrm{N}$ de uma parcela para a outra. A adubação básica foi de $120 \mathrm{~kg} \mathrm{ha}^{-1}$ de $\mathrm{P}_{2} \mathrm{O}_{5}$ (superfosfato triplo) e $80 \mathrm{~kg} \mathrm{ha}^{-1}$ de $\mathrm{K}_{2} \mathrm{O}(\mathrm{KCl})$ para todos os locais, no sulco de plantio, por ocasião da semeadura do arroz.

Utilizou-se a cultivar Metica 1, com espaçamento de $20 \mathrm{~cm}$ entre linhas e densidade de 100 sementes por metro. As parcelas foram inundadas aos 30 dias após o plantio e drenadas uma semana antes da colheita. A produtividade de grãos foi avaliada em áreas de $3 \times 3 \mathrm{~m}$ e a massa de matéria seca das plantas em $1 \mathrm{~m}$ linear de fileira por parcela. $\mathrm{O}$ material de parte aérea e grãos foi secado em estufa a $65^{\circ} \mathrm{C}$, moído e digerido com ácido sulfúrico para determinação de $\mathrm{N}$ pelo método de Kjeldahl (Moraes \& Rabelo, 1986). Os dados obtidos foram submetidos à análise de variância e as médias dos tratamentos comparadas pelo teste de Tukey, a 5\% de probabilidade.

\section{Resultados e Discussão}

A interação anos $x$ locais foi significativa em relação à produção de grãos e à forma de aplicação de $\mathrm{N}$ (Tabela 2). O efeito predominante dos anos indica a importância da variação ano para ano, nas condições climáticas, com relação às respostas das variáveis avaliadas. Esta interação também mostra a importância dos locais na variabilidade da produção. Em Formoso do
Araguaia, a produção foi maior no tratamento $\mathrm{T}_{2}$ nos dois anos de cultivo. Nesse mesmo local, a produtividade foi maior no segundo ano em relação ao primeiro ano de cultivo. Essa diferença pode estar relacionada aos fatores climáticos favoráveis no segundo ano, em relação ao primeiro. Na Lagoa da Confusão, não houve diferença na produção nos dois primeiros anos de cultivo, entretanto, no terceiro, a produção foi menor em relação aos dois primeiros, mas, na média de anos e locais, $\mathrm{o}$ tratamento de época de aplicação de $\mathrm{N}$ influenciou a produção (Tabela 2). Na média geral, a produção máxima foi obtida com os tratamentos $\mathrm{T}_{2}$ e $\mathrm{T}_{3}$.

$\mathrm{Na}$ Ásia, onde existe a maior área de arroz irrigado no mundo, na década de 80 , a recomendação de parcelamento de $\mathrm{N}$ era $2 / 3$ no plantio e $1 / 3$ na época da iniciação do primórdio floral (De Datta et al., 1988). No entanto, nessa mesma região, na década de 90, a aplicação de $\mathrm{N}$ em quatro parcelas iguais (no plantio, no perfilhamento ativo, na iniciação do primórdio floral, na floração) mostrou-se mais eficiente na recuperação de $\mathrm{N}$ pelo arroz (70\% a 80\%; Peng et al., 1996). Bronson et al. (2000), em casa de vegetação, constataram que o tratamento que recebeu $2 / 3$ do $N$ no plantio e $1 / 3$ na iniciação do primórdio floral apresentou maior produtividade, com 54\% de eficiência de recuperação.

Fageria \& Baligar (1999) em casa de vegetação, utilizando solo de várzea do Brasil, observaram que a aplicação de todo o $\mathrm{N}$ no plantio proporcionou produção máxima em relação ao parcelamento, em duas ou três épocas. Esses autores concluíram, ainda, que a aplica-

Tabela 2. Produção de grãos de arroz irrigado nas diferentes épocas de aplicação de N, em cinco cultivos ${ }^{(1)}$.

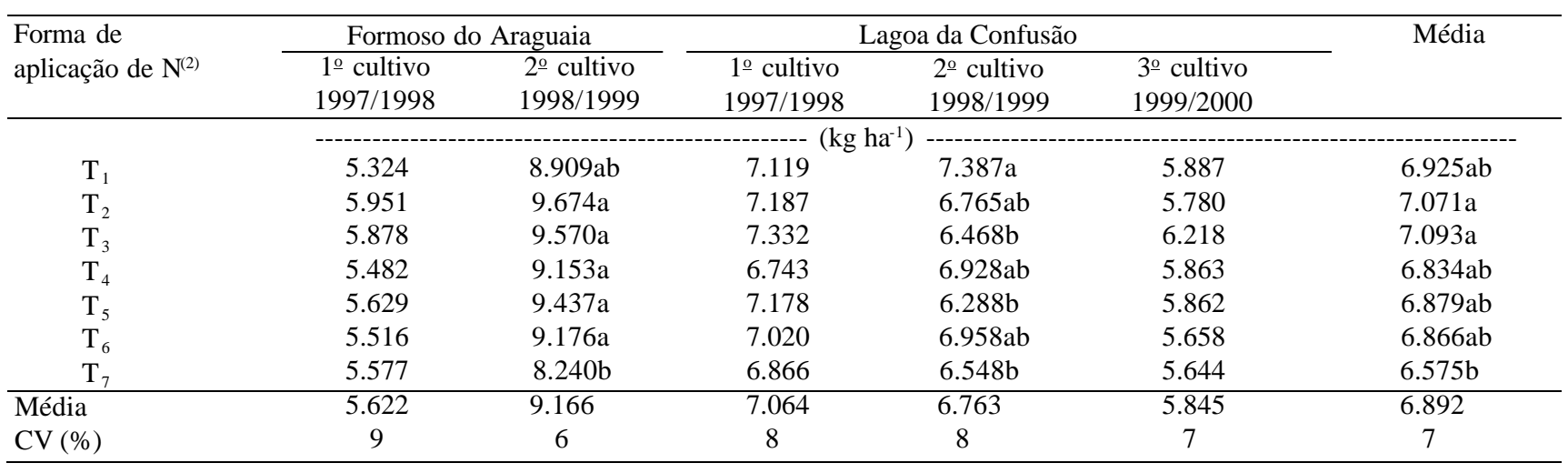

${ }^{(1)}$ Médias seguidas da mesma letra, na coluna, não diferem entre si pelo teste de Tukey a $5 \%$ de probabilidade. ${ }^{(2)} \mathrm{T}_{1}$ : todo o $\mathrm{N}$ no plantio; $\mathrm{T}_{2}: 1 / 3 \mathrm{~N}$ no plantio $+1 / 3 \mathrm{~N} 45$ dias após o plantio $+1 / 3 \mathrm{~N}$ na iniciação do primórdio floral; $\mathrm{T}_{3}: 1 / 2 \mathrm{~N}$ no plantio $+1 / 2 \mathrm{~N} 45$ dias após o plantio; $\mathrm{T}_{4}$ : $1 / 2 \mathrm{~N}$ no plantio $+1 / 2 \mathrm{~N}$ na iniciação do primórdio floral; $\mathrm{T}_{5}: 2 / 3 \mathrm{~N}$ no plantio $+1 / 3 \mathrm{~N} 45$ dias após o plantio; $\mathrm{T}_{6}: 2 / 3 \mathrm{~N}$ no plantio $+1 / 3 \mathrm{~N}$ na iniciação do primórdio floral; $\mathrm{T}_{7}: 1 / 3 \mathrm{~N}$ no plantio $+2 / 3 \mathrm{~N} 20$ dias após o plantio. 
ção de $\mathrm{N}$ na época do emborrachamento e da floração não aumentou a produção em relação à aplicação realizada em estádio anterior. A aplicação de $\mathrm{N}$ no estádio de desenvolvimento da planta resultou em maior número de panículas, o que determinou aumento de produtividade. Bronson et al. (2000) também relataram que, quando a maior quantidade de $\mathrm{N}$ foi aplicada no início do ciclo, houve aumento no número de perfilhos e de panículas e, conseqüentemente, maior produtividade. Fageria et al. (1999) e Fageria \& Baligar (2001) obtiveram produção máxima na cultura de arroz irrigado com a aplicação de $90 \mathrm{~kg} \mathrm{ha}^{-1}$ de $\mathrm{N}$ em três parcelas iguais, no plantio, no perfilhamento ativo e na iniciação do primórdio floral. Em virtude do menor parcelamento no tratamento $T_{3}$ em comparação com o tratamento $T_{2}, o$ tratamento $\mathrm{T}_{3}$ pode ser recomendado para os produtores de arroz irrigado.

$\mathrm{O}$ tratamento $\mathrm{T}_{7}$ resultou na menor produção em comparação aos outros tratamentos. Este fato pode estar relacionado com a perda de grande quantidade de $\mathrm{N}$, através de lixiviação e desnitrificação, pois o perfilhamento iniciou-se aos 20 dias após a semeadura e a cultura foi inundada 30 dias após a semeadura. Portanto, o período de dez dias entre a iniciação de perfilhamento até a inundação é suficiente para que a uréia possa ser transformada em nitrato (Wilson et al., 1990). Após a inundação, o nitrato é perdido por desnitrificação (Wilson et al., 1990, 1998). Na cultura do arroz irrigado, o grau de perda de $\mathrm{N}$ e sua eficiência de uso são altamente dependentes do manejo da água. Sob condições similares de manejo de N, foi relatada alta perda de $\mathrm{N}$ com inundação intermitente e drenagem em comparação com inundação contínua (Fageria et al., 2003).
A perda de $\mathrm{N}$ na cultura de arroz irrigado é mínima quando ele é incorporado ao solo em relação a sua aplicação superficial (Reddy \& Patrick Junior, 1986). Nos tratamentos $\mathrm{T}_{2}$ e $\mathrm{T}_{3}$, uma parte do $\mathrm{N}$ foi aplicada em cobertura no estádio de perfilhamento ativo, que pode ser definido como período em que o aumento do número dos perfilhos por unidade de tempo é máximo, durante o período de crescimento da cultura (Murayama, 1995). Nesse estádio, a absorção de N pode ser máxima pelo aumento do número de perfilhos, que determina o número de panículas e, conseqüentemente, a produção (Fageria \& Baligar, 1999). A aplicação de N em três vezes, antes da inundação, na iniciação do primórdio floral e na iniciação do primórdio floral +10 dias, é extensivamente usada em alguns estados do Sul do Estados Unidos, onde o arroz irrigado é cultivado (Slaton et al., 1994; Wilson et al., 1998). As cultivares de arroz de porte baixo são resistentes ao acamamento, necessitam mais $\mathrm{N}$ durante a fase inicial do crescimento e são menos responsivas à aplicação de $\mathrm{N}$ na fase tardia do crescimento (Norman et al., 1996, 1997).

Na média dos cinco cultivos, a produção de grãos foi influenciada significativamente pelo tratamento de fungicida (Tabela 3). O tratamento com $200 \mathrm{~g} / 100 \mathrm{~kg}$ de semente produziu $170 \mathrm{~kg} \mathrm{ha}^{-1}$ a mais que o tratamento testemunha. Não houve, entretanto, diferença significativa, quando a dose de fungicida foi aumentada de 200 para $400 \mathrm{~g} / 100 \mathrm{~kg}$ de semente. Prabhu \& Filippi (1993) relataram que $200 \mathrm{~g}$ de pyroquilon por $100 \mathrm{~kg}$ de semente foi o melhor tratamento no controle de brusone, na cultura do arroz em terras altas. Não ocorreu interação significativa entre fungicida e época de aplicação de N, mostrando que esses dois fatores tiveram efeitos independentes no aumento da produção.

Na média dos quatro cultivos, a quantidade de matéria seca da parte aérea foi afetada significativamente

Tabela 3. Produção de grãos de arroz irrigado em razão do tratamento da semente com pyroquilon ${ }^{(1)}$.

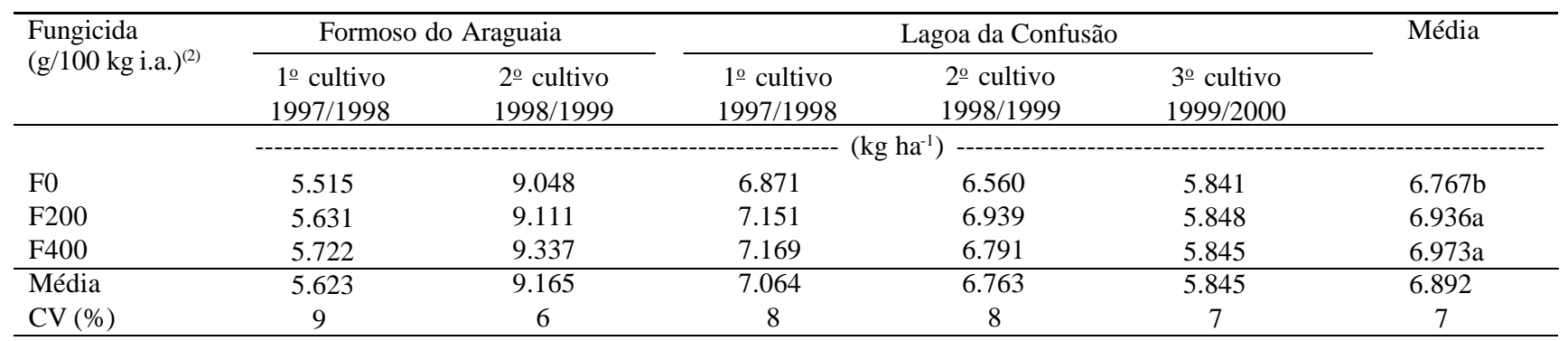

${ }^{(1)}$ Médias seguidas da mesma letra, na coluna, não diferem significativamente entre si pelo teste de Tukey a 5\% de probabilidade. (2)F0: fungicida $0 \mathrm{~g} / 100 \mathrm{~kg}$ de semente; F200: fungicida $200 \mathrm{~g} / 100 \mathrm{~kg}$ de semente; F400: fungicida $400 \mathrm{~g} / 100 \mathrm{~kg}$ de semente. 
pela época de aplicação de $\mathrm{N}$ (Tabela 4). O valor máximo de matéria seca da parte aérea foi obtido no tratamento $\mathrm{T}_{5}$, enquanto o menor foi obtido no tratamento $\mathrm{T}_{4}$. Os tratamentos $\mathrm{T}_{2}$ e $\mathrm{T}_{3}$ propiciaram a máxima produção de grãos e apresentaram massa da matéria seca da parte aérea semelhante à dos tratamentos $\mathrm{T}_{1}, \mathrm{~T}_{6}$, e $\mathrm{T}_{7}$. A massa de matéria seca apresenta, geralmente, relação quadrática com a produção de grãos (Fageria, \& Baligar, 2001); portanto, valor máximo de massa de matéria seca não significa, necessariamente, máxima produção de grãos.
$\mathrm{O}$ teor de $\mathrm{N}$ na parte aérea e nos grãos foi determinado separadamente, porém o efeito significativo do tratamento de época de aplicação de $\mathrm{N}$ somente foi obtido na acumulação de N nos grãos (Tabela 4). Em Formoso do Araguaia, esta acumulação foi, no segundo ano de cultivo, quase o dobro em relação ao primeiro; esta diferença está relacionada à maior produção de grãos no segundo ano. Em Lagoa da Confusão a quantidade de grãos produzida nos dois anos de cultivo foi semelhante, mostrando que não houve diferença na acumulação de $\mathrm{N}$ de um ano para outro. Na média geral, a acumulação máxima de $\mathrm{N}$ nos grãos foi obtida no tratamento $\mathrm{T}_{2} \mathrm{e}$

Tabela 4. Matéria seca da parte aérea, acumulação de $\mathrm{N}$ nos grãos e acumulação de $\mathrm{N}$ na parte aérea de arroz irrigado nos diferentes tratamentos e forma de aplicação de nitrogênio ${ }^{(1)}$.

\begin{tabular}{|c|c|c|c|c|c|}
\hline \multirow{2}{*}{$\begin{array}{l}\text { Forma de aplicação } \\
\text { de } \mathrm{N}^{(2)}\end{array}$} & \multicolumn{2}{|c|}{ Formoso do Araguaia } & \multicolumn{2}{|c|}{ Lagoa da Confusão } & \multirow[t]{2}{*}{ Média } \\
\hline & 1으 cultivo $1997 / 1998$ & 2o cultivo $1998 / 1999$ & 1ㅇ cultivo $1997 / 1998$ & 2o cultivo $1998 / 1999$ & \\
\hline & \multicolumn{5}{|c|}{ Massa de matéria seca $\left(\mathrm{kg} \mathrm{ha}^{-1}\right)$} \\
\hline $\mathrm{T}_{1}$ & $7.162 \mathrm{ab}$ & 9.216 & 7.415 & 7.869 & $7.916 \mathrm{ab}$ \\
\hline $\mathrm{T}_{2}$ & $7.425 \mathrm{ab}$ & 9.352 & 7.512 & 7.769 & $8.015 \mathrm{ab}$ \\
\hline $\mathrm{T}_{3}$ & $7.656 \mathrm{ab}$ & 9.671 & 7.840 & 6.854 & $8.005 \mathrm{ab}$ \\
\hline $\mathrm{T}_{4}$ & $6.249 b$ & 9.161 & 6.533 & 7.771 & $7.429 b$ \\
\hline $\mathrm{T}_{5}$ & $8.495 \mathrm{a}$ & 10.089 & 8.065 & 7.059 & $8.427 \mathrm{a}$ \\
\hline $\mathrm{T}_{6}$ & $6.789 a b$ & 8.774 & 7.662 & 7.936 & 7.790ab \\
\hline $\mathrm{T}_{7}$ & $7.721 \mathrm{ab}$ & 8.993 & 7.112 & 7.484 & $7.828 \mathrm{ab}$ \\
\hline Média & 7.357 & 9.322 & 7.448 & 7.535 & \\
\hline Teste F & $*$ & ns & ns & ns & ** \\
\hline $\mathrm{CV}(\%)$ & 16 & 14 & 14 & 16 & 15 \\
\hline \multicolumn{6}{|c|}{ Acumulação de $\mathrm{N}$ nos grãos $\left(\mathrm{kg} \mathrm{ha}^{-1}\right)$} \\
\hline $\mathrm{T}_{1}$ & 53 & $101 \mathrm{ab}$ & 86 & $88 \mathrm{a}$ & $82 \mathrm{ab}$ \\
\hline $\mathrm{T}_{2}$ & 62 & $121 \mathrm{a}$ & 83 & $74 \mathrm{ab}$ & $85 \mathrm{a}$ \\
\hline $\mathrm{T}_{3}$ & 61 & $111 \mathrm{ab}$ & 84 & 72ab & $82 \mathrm{ab}$ \\
\hline $\mathrm{T}_{4}$ & 62 & $110 \mathrm{ab}$ & 83 & $85 \mathrm{ab}$ & $85 \mathrm{a}$ \\
\hline $\mathrm{T}_{5}$ & 55 & $111 \mathrm{ab}$ & 84 & $69 \mathrm{~b}$ & $80 \mathrm{ab}$ \\
\hline $\mathrm{T}_{6}$ & 58 & $105 \mathrm{ab}$ & 85 & $80 \mathrm{ab}$ & $82 \mathrm{ab}$ \\
\hline $\mathrm{T}_{7}$ & 56 & $90 \mathrm{~b}$ & 84 & $71 \mathrm{ab}$ & $75 b$ \\
\hline Média & 58 & 107 & 84 & 77 & 82 \\
\hline Teste F & ns & $* *$ & ns & $* *$ & $* *$ \\
\hline $\mathrm{CV}(\%)$ & 11 & 9 & 11 & 11 & 11 \\
\hline \multicolumn{6}{|c|}{ Acumulação de $\mathrm{N}$ na parte aérea $\left(\mathrm{kg} \mathrm{ha}^{-1}\right)$} \\
\hline $\mathrm{T}_{1}$ & 42 & 57 & 51 & 67 & 54 \\
\hline $\mathrm{T}_{2}$ & 48 & 58 & 56 & 50 & 53 \\
\hline $\mathrm{T}_{3}$ & 40 & 55 & 50 & 49 & 49 \\
\hline $\mathrm{T}_{4}$ & 39 & 57 & 48 & 68 & 53 \\
\hline $\mathrm{T}_{5}$ & 42 & 61 & 55 & 52 & 53 \\
\hline $\mathrm{T}_{6}$ & 36 & 59 & 48 & 62 & 51 \\
\hline $\mathrm{T}_{7}$ & 40 & 52 & 51 & 48 & 48 \\
\hline Média & 41 & 57 & 51 & 57 & \\
\hline Teste F & $\mathrm{ns}$ & ns & ns & ns & ns \\
\hline $\mathrm{CV}(\%)$ & 14 & 19 & 21 & 22 & 12 \\
\hline
\end{tabular}


pode estar relacionada com a maior produção relativa de grãos desse tratamento. Na média, a acumulação de $1 \mathrm{~kg}$ de $\mathrm{N}$ produziu $87 \mathrm{~kg}$ de grãos, resultado semelhante aos de Fageria \& Baligar (1996) e Fageria et al. (1997) no uso de N na produção de grãos de arroz irrigado.

Não houve diferença significativa entre tratamentos na acumulação de $\mathrm{N}$ na parte aérea, porém na média de quatro cultivos, $71 \%$ a menos de $\mathrm{N}$ foram acumulados na parte aérea em comparação com os grãos (Tabela 4). Vários trabalhos mostram que maior quantidade de $\mathrm{N}$ é acumulada nos grãos do arroz em relação ao $\mathrm{N}$ acumulado na parte aérea (Yoshida, 1981; Fageria \& Baligar, 1996; Fageria et al., 1997).

\section{Conclusões}

1. A aplicação de $90 \mathrm{~kg} \mathrm{ha}^{-1}$ de $\mathrm{N}$, em duas partes iguais, na semeadura e no estádio de perfilhamento ativo (45 dias após o plantio), ou em três partes iguais, no plantio, no perfilhamento ativo e no início do primórdio floral, estimula a produção de arroz 'Metica' em cultivo irrigado.

2. O tratamento de sementes com $200 \mathrm{~g} / 100 \mathrm{~kg}^{-1}$ ou $400 \mathrm{~g} / 100 \mathrm{~kg}^{-1}$ de pyroquilon promove o controle da brosone e melhora o rendimento de arroz irrigado.

3. Não há interação significativa entre forma de aplicação de $\mathrm{N}$ e tratamento com fungicida, no cultivo do arroz irrigado.

\section{Referências}

BALASUBRAMANIAN, V.; LADHA, J.K.; DENNING, G. L Resource management in rice systems: nutrients. Los Baños: International Rice Research Institute, 1999. 355p.

BRONSON, K.F.; HUSSAIN, F.; PASUQUIN, E.; LADHA, J.K. Use of ${ }^{15} \mathrm{~N}$-labeled soil in measuring nitrogen fertilizer recovery efficiency in transplanted rice. Soil Science Society of America Journal, v.64, p.235-239, 2000.

DE DATTA, S.K.; BURESH, R.J.; SAMSON, M.I.; KAI-RONG, W. Nitrogen use efficiency and nitrogen- 15 balances in broadcastseeded flooded and transplanted rice. Soil Science Society of America Journal, v.52, p.849-855, 1988.

EMBRAPA. Centro Nacional de Pesquisa de Solos (Rio de Janeiro, RJ). Manual de métodos de análise de solo. 2.ed. Rio de Janeiro, 1997. $212 \mathrm{p}$

FAGERIA, N.K.; BALIGAR, V.C. Lowland rice response to nitrogen fertilization. Communications in Soil Science and Plant Analysis, v.32, p.1405-1429, 2001.

FAGERIA, N.K.; BALIGAR, V.C. Response of lowland rice and common bean grown in rotation to soil fertility levels on a varzea soil. Fertilizer Research, v.45, p.13-20, 1996.
FAGERIA, N.K.; BALIGAR, V.C. Yield and yield components of lowland rice as influenced by timing of nitrogen fertilization. Journal of Plant Nutrition, v.22, p.23-32, 1999.

FAGERIA, N.K.; BALIGAR, V.C.; JONES, C.A. Growth and mineral nutrition of field crops. $2^{\text {nd }}$ ed. New York: M. Dekker, 1997. 624p.

FAGERIA, N.K.; SLATON, N.A.; BALIGAR, V.C. Nutrient management for improving lowland rice productivity and sustainability. Advances in Agronomy, v.80, p.63-152, 2003.

FILIPPI, M.C.; PRABHU, A.S. Relationship between panicle blast severity and mineral nutrient content of plant tissue in upland rice. Journal of Plant Nutrition, v.21, p.1577-1587, 1998.

HUBER, D.M.; WATSON, R.D. Nitrogen form and plant disease. Annual Review of Phytopathology, v.12, p.139-165, 1974.

KUNDU, D.K.; LADHA, J.K.; LAPITAN-DE-GUZMAN, E. Tillage depth influence on soil nitrogen distribution and availability in a rice lowland. Soil Science Society of America Journal, v.60, p.1153-1159, 1996.

MORAES, J.F.V.; RABELO, N.A. Um método simples para a digestão de amostras de plantas. Goiânia: Embrapa-CNPAF, 1986. 12p. (Documentos, 12).

MURAYAMA, N. Development and senescence. In: MATSUO, T.; KUMAZAWA, K.; ISHII, R.; ISHIHARA, K.; HIRATA, H. (Ed.). Science of the rice plant: physiology. Tokyo: Food and Agriculture Policy Research Center, 1995. p.119-178.

NORMAN, R.J.; WILSON JUNIOR, C.E.; SLATON, N.A.; GRAVOIS, K.A.; MOLDENHAUER, K.A.K. Grain yield response of new rice cultivar/varieties to nitrogen fertilization. In: NORMAN, R.J.; JOHNSTON, T.H.; WELLS, B.R. (Ed.). Rice research studies 1996. Fayetteville: Arkansas Agricultural Experiment Station, 1997. p.125-129. (Arkansas Agricultural Experiment Station. Research Series, 456).

NORMAN, R.J.; WILSON JUNIOR, C.E.; WELLS, B.R.N.; SLATON, A.; BEYROUTY, C.A.K.; MOLDENHAUER, A.K.; GRAVOIS, K.A. Management of agronomic factors in rice production. In: NORMAN, R.J.; WELLS, B.R. (Ed.). Arkansas rice research studies 1995. Fayetteville: Arkansas Agricultural Experiment Station, 1996. p.174-177. (Arkansas Agricultural Experiment Station. Research Series, 453).

PENG, S.; GARCIA, F.V.; LAZA, R.C.; SANICO, A.L.; VISPERAS, R.M.; CASSMAN, K.G. Increased nitrogen use efficiency using a chlorophyll meter in high yielding irrigated rice. Field Crops Research, v.47, p.243-252, 1996.

PRABHU, A.S.; FILIPPI, M.C. Seed treatment with pyroquilon for the control of leaf blast in Brazilian upland rice. International Journal of Pest Management, v.39, p.347-353, 1993.

REDDY, K.R.; PATRICK JUNIOR, W.H. Denitrification losses in flooded rice fields. In: DE DATTA, S.K.; PATRICK JUNIOR, W.H. (Ed.). Nitrogen economy of flooded rice soils. Dordrecht: M. Nijhoff, 1986. p.99-116.

SANTOS, A.B.; PRABHU, A.S.; AQUINO, A.R.L. Épocas, modos de aplicação e níveis de nitrogênio sobre brusone e produtividade de 
arroz de sequeiro. Pesquisa Agropecuária Brasileira, v.21, p.697-707, 1986.

SLATON, N.; NORMAN, A.R.J.; WELLS, B.R.; MILLER, D.M.; HELMS, R.S.; BEYROUTY, C.A.; WILSON JUNIOR, C.E. Efficient use of fertilizer. In: HELMS, R.S. (Ed.). Rice production handbook. Little Rock: University of Arkansas, 1994. p.42-54. (Miscellany Publication, 192).

WANG, Z.; MacKILL, D.J.; BONMANN, J.M. Inheritance of partial resistance to blast in indica rice cultivars. Crop Science, v.29, p.848-853, 1989.
WILSON, C.E.; BOLLICH, P.K.; NORMAN, R.J. Nitrogen application timing effects on nitrogen efficiency of dry-seeded rice. Soil Science Society of America Journal, v.62, p.959-964, 1998. WILSON, C.E.; NORMAN, R.J.; WELLS, B.R. Dicyandiamide influence on uptake of preplant-applied fertilizer nitrogen by rice. Soil Science Society of America Journal, v.54, p.1157-1161, 1990.

YOSHIDA, S. Fundamentals of rice science. Los Baños: International Rice Research Institute, 1981. 269p.

Recebido em 9 de junho de 2003 e aprovado em 10 de outubro de 2003 